Case Reports

\title{
Immune-Mediated Myocarditis Associated with Leptospirosis in 6 Years Old Labrador Retriever
}

\author{
${ }^{1,3}$ Oleinikov Dmitrii and ${ }^{2}$ Letunoskaja Anna \\ ${ }^{I}$ City Oncology Center 'Praid', Saint-Petersburg, Russian Federation \\ ${ }^{2}$ Veterinary Clinic of Neurology, Traumatology and Intensive Care, Saint-Petersburg, Russian Federation \\ ${ }^{3}$ Almazov National Medical Research Center, IEM, Saint-Petersburg, 197341 Russian Federation
}

Article history

Received: 14-06-2018

Revised: 10-09-2018

Accepted: 04-10-2018

Corresponding Author:

Oleinikov Dmitrii,

City oncology center 'Praid',

Saint-Petersburg, Russian

Federation, Utochkinast. 3

building 2, Saint-Petersburg,

Russian Federation

Tel: +7 812 388-30-51

+7 $981962-66-13$

Fax: 7812 388-30-51

Email: wolfberg.guard@gmail.com

\section{Introduction}

\section{Case Report}

About 6 years old, unvaccinated non-spared male Labrador retriever was presented to the veterinary hospital with clinical signs of 10 days long weakness and fatigue. Appetite was normal, but thirst was increased. In the previous veterinary hospital, bacterial enteritis was suggested and was treated with antibiotics (Amoxicillin+Clavulonate) and prednisone in standard doses. At the first therapeutic examination of the patient, a pallor and passiveness were admitted, but dog stayed alert. Body temperature was $38.2^{\circ} \mathrm{C}$. The patient was sent for blood (CBC and biochemistry profiles), urine analysis and observing radio- and ultrasonography were performed. Radiography revealed non-significant changes in the bronchial pattern, but peribronchial tissue had slightly increased opacity. Ultrasonography examination showed mild bilateral nephritis, prostatitis and chronic hepatitis. Urine analysis showed mild proteinuria and increased protein/creatinine ratio $-1,18$. Clinical blood examination showed raised PCV (71,1\%; reference data 35\%-55\%), slightly increased RBC $\left(8,9^{*} 10^{12} / 1\right.$; reference data $\left.5.5-8.5^{*} 1012 / 1\right)$ and high hemoglobin concentrations (208 g/l; reference data 120 $180 \mathrm{~g} / \mathrm{l})$ while leucocytes were in normal limits $\left(12 * 10^{9} /\right.$; r reference data $\left.7-17 * 10^{9} /\right)$ with non-significant neutrophilia (74\% in leukogram, but the absolute count was unchanged). Biochemistry findings included increased BUN (20 mmol/1; reference data 3.5-9.2 $\mathrm{mmol} / \mathrm{l})$, Creatinine $(184,9 \mathrm{mmol} / \mathrm{l}$; reference data $44-$ $137 \mathrm{mmol} / \mathrm{l})$, ALT (234 IU/l; reference data 6-70 IU/l), Alkaline phosphatase (1,698 IU/L; reference data 15-80 IU/l), Phosphates (2,04 mmol/1; reference data $0,94-1,71$ $\mathrm{mmol} / \mathrm{l})$ and Potassium $(6,75 \mathrm{mmol} / \mathrm{l}$; reference data 3,5$5,5 \mathrm{mmol} / \mathrm{l})$. Other parameters were within normal limits. Preliminary diagnose was nephritis and relevant treatment was recommended. Due to prostate enlargement castration was advised. In addition, blood 
samples were collected to detect infectious agents (Leptospira spp., Brucella canis) by PCR (qRT-PCR) and ELISA IgM count for Toxoplasmosis.

Seven days later dog came with increased fatigue and thirst and absence of appetite, medications were not provided. Blood analysis (CBC and blood chemistry) were repeated, also blood pressure (mean arterial pressure $143 \mathrm{~mm} \mathrm{Hg}$ ) and glucose concentration were measured. Clinical and biochemistry didn't differ from previous data, except potassium, it increased to $7,47 \mathrm{mmol} / 1$ (reference data 3,5-5,5mmol/1) and hypoglycemia presented $(2,6 \mathrm{mmol} / \mathrm{l}$; reference data $3,5-$ $6,5 \mathrm{mmol} / \mathrm{l})$. The patient was forwarded to the intensive care unit for stabilization. Infusion therapy was aimed for rehydration, acid-base and electrolyte balance restoration, 40\% Glucose solution was administrated for hypoglycemia control. In spite of continuous supplementation, glucose level stayed low or rapidly decreases. To exclude endocrinopathies, blood insulin concentration was measured and test for Addison's disease with Synacthen was performed. Results for both tests were in reference limits: Insulin - concentration $8 \mathrm{mcU} / \mathrm{ml}$ (reference data 8-20 $\mathrm{mcU} / \mathrm{ml}$ ); Cortisol after stimulation was $250 \mathrm{nmol} / 1$ (reference data $200-600 \mathrm{nmol} / \mathrm{l}$ )

Despite infusion therapy, the clinical condition of the dog was worsening. Due to the raise of systemic blood pressure, fatigue and dyspnea patient was sent on cardiac examination. The dog was passive and depressed at the presentation, the visible mucosa was pale and capillary refilling time was slowed. Auscultation revealed I/VI systolic murmur on a mitral valve projection, auscultated rhythm consist of a heart beats with normal rate and effective pulse wave and paroxysm of 5-6 rapid beats with weak pulse wave, palpated on femoral artery.

Two-dimensional echocardiography showed mild hypertrophy of left ventricular walls, with hypokinetic segments. The chambers were not dilated, there was no evidence of valves damage. Dopplerography revealed first-grade left ventricular diastolic dysfunction. Systolic function was unchanged except tachycardia paroxysms. Effusion fraction calculated by the Simpson method during sinus contraction was $51.6 \%$, while during tachycardia - 29.3\% (Fig. 1).

Six-lead electrocardiography identified several sinus complexes and paroxysms of ventricular tachycardia up to 30-40 beats(cycle length 390-400 ms) (Fig. 2).

Myocarditis was suspected, additionally recommended to take blood tests for Bartonellosis (PCR for Bart. henselae\&vinsonii), Borreliosis (PCR for Borr. burgdorferi), Leptospirosis (microagglutination test for Lept. canicola, Lept. Pomona, Lept. icterohaemorrhagiae) Troponin I.

All performed PCR tests for infectious agents were negative, Troponin level was $0.85 \mathrm{ng} / \mathrm{ml}$ (reference data 0.0-0.06 ng/ml). Leptospirosismicroagglutination test was performed to obtain antibodies titer, it reached the level of 1:800 to Leptospiracanicola (Reference limit 1:400).

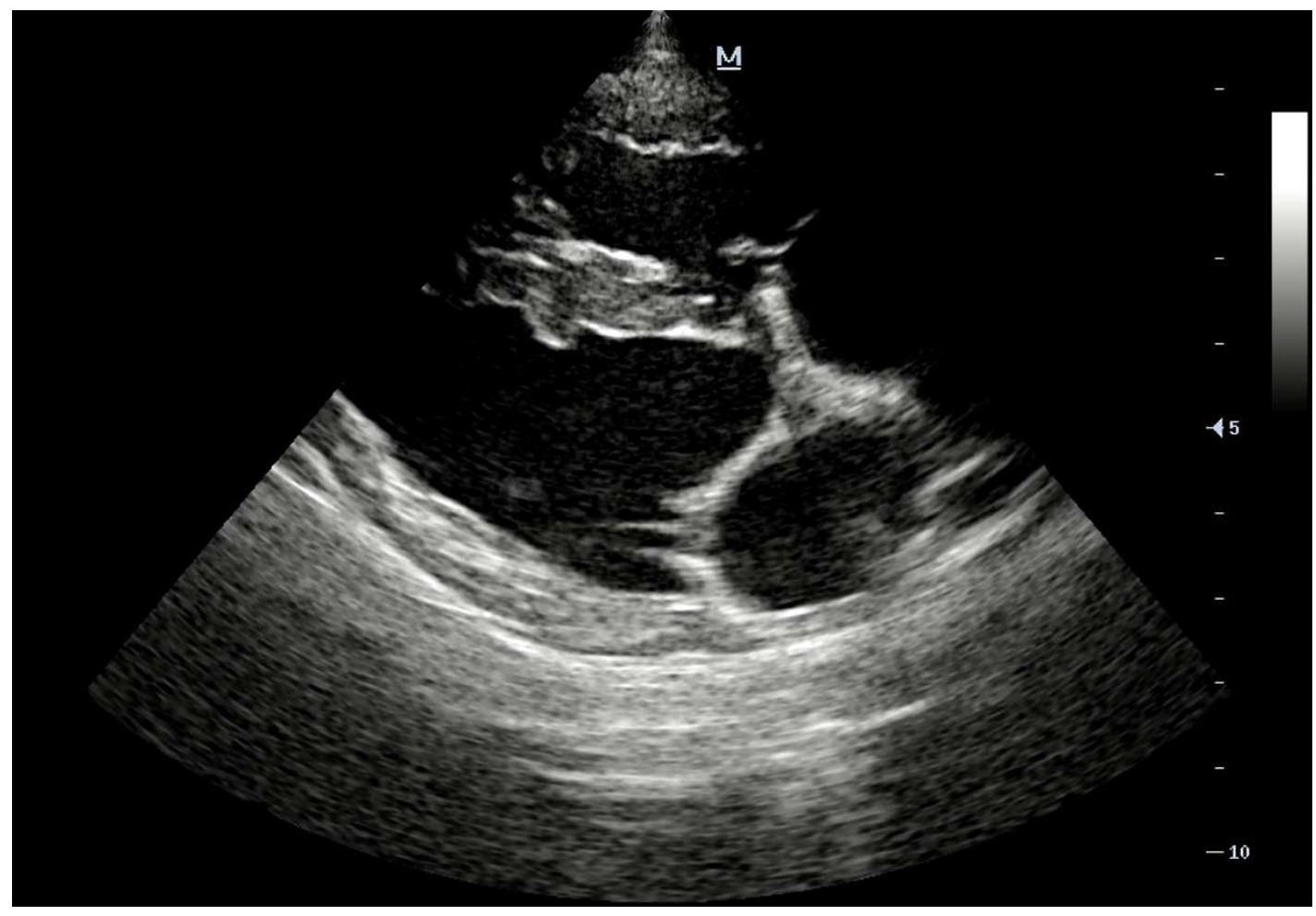

Fig. 1: Transthoracic ultrasonography in right parasternal long axis. Non-homogeneous myocardium with segmental hypertrophy and hypokinesia. Sustained systolic function 


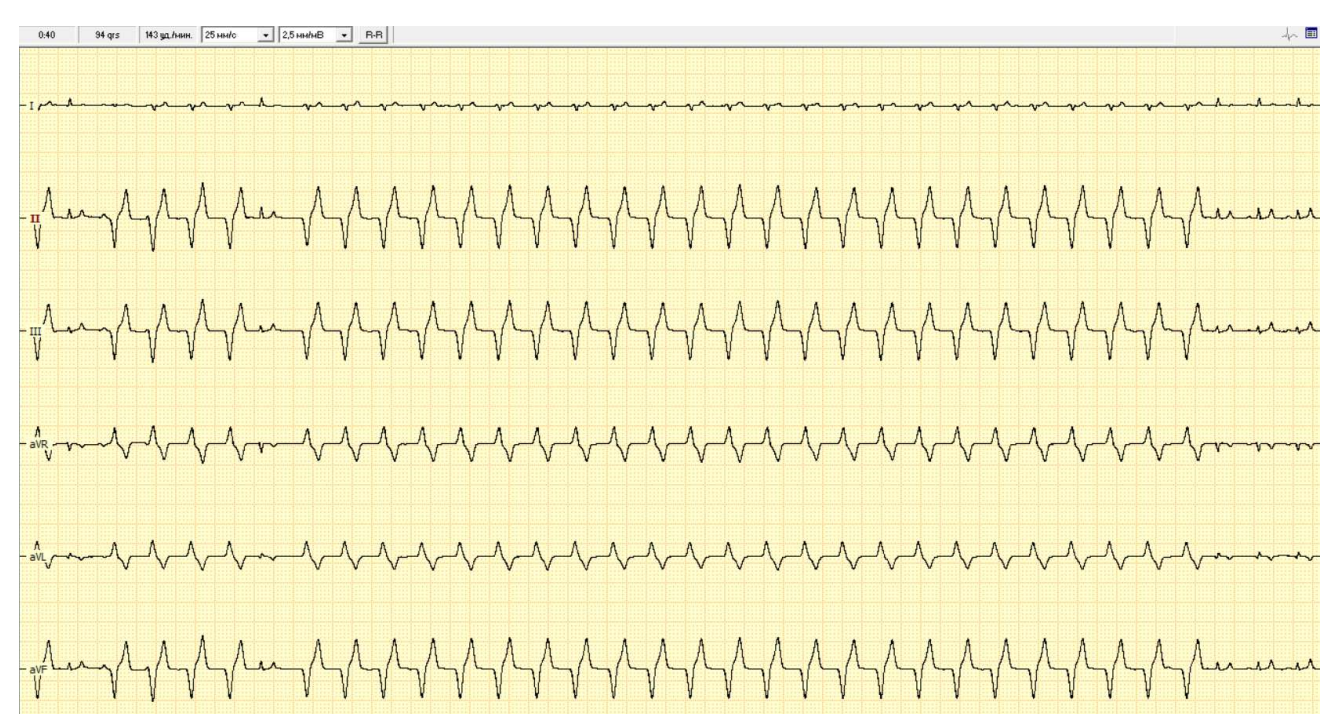

Fig. 2: Six-lead electrocardiography. Paroxysms of ventricle tachycardia with 390-410 ms R-R length.Monotopic, monomorphic, with right bundle branch block morphology. Isolated sinus complexes, with $\mathrm{P}$ hide by the previous premature complex

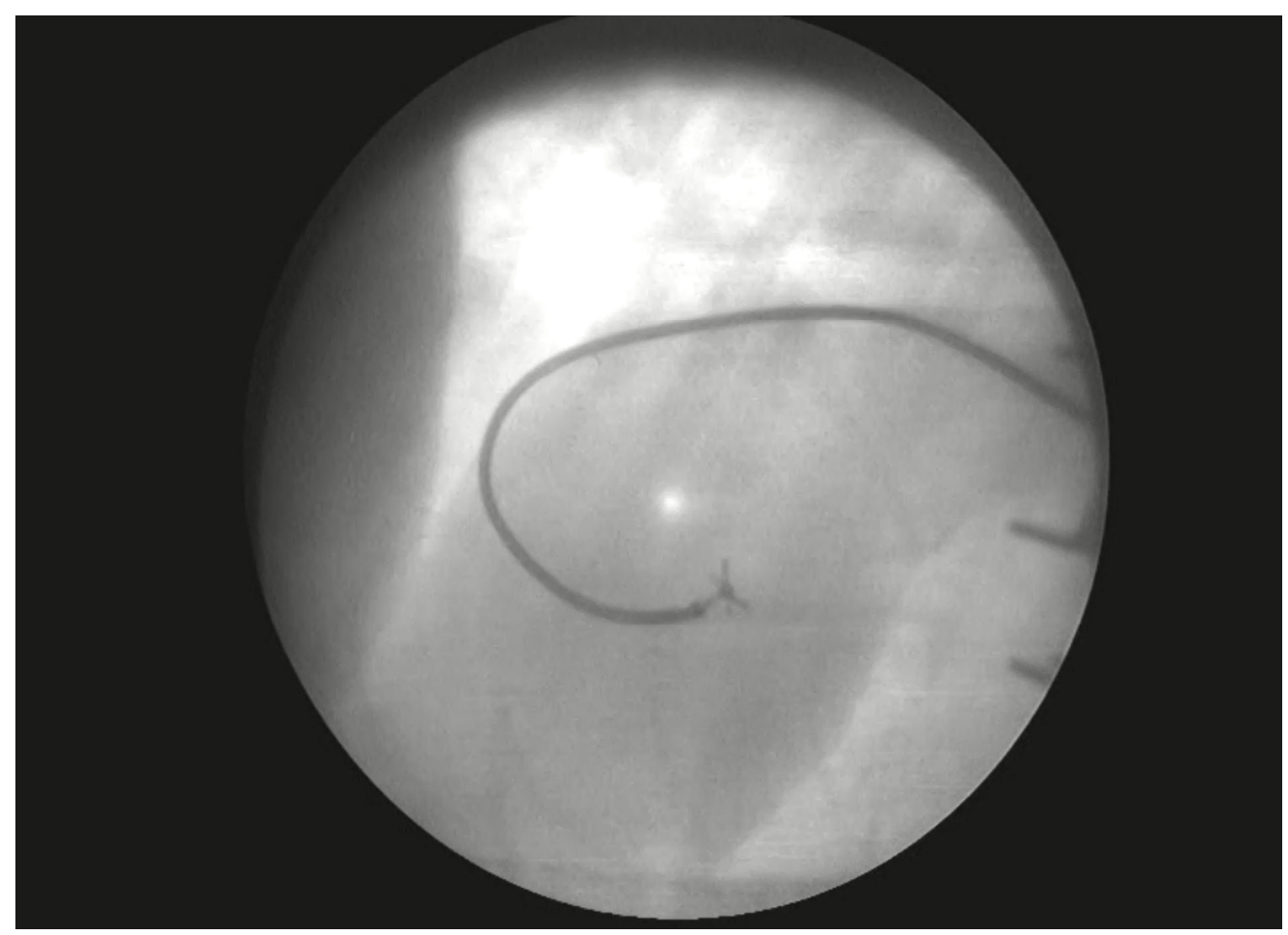

Fig. 3: Fluoroscopy associated endomyocardial biopsy

In addition to the main therapy protocol amiodarone, constant rate infusion with $10 \mathrm{mg} / \mathrm{kg} / \mathrm{hr}$ dose and prednisone in $1 \mathrm{mg} / \mathrm{kg}$ dose BID were added.

In a parallel, was obtained an endomyocardial biopsy. The procedure was made in standard technic with jugular vein access and under fluoroscopy control (Fig. 3). For manipulation dog was sedated with fentanyl $(2 \mathrm{mg} / \mathrm{kg})$. Obtained samples were conserved in a standard buffered formaldehyde solution and sent to the histopathology laboratory. Additionally, biopsy PCR test for Bartonellosis (Bart. henselae\&vinsonii), Borreliosis (Borr. burgdorferi), Toxoplasmosis (T.gondii) and Leptospirosis (Leptospira spp.) were taken and stored in $70^{\circ}$ ethanol than sent to the laboratory. All the performed tests were negative, except for Leptospira spp., which was positive. 
The histopathologic exam revealed severe lymphocytic infiltration of the interventricular septum and right ventricular free wall samples. Numerous lymphocytes were visualized in intermyofibrillar spaces. Cardiomyocytes were severally damaged with signs of coagulation necrosis, degeneration, atrophy and dystrophy. In some fields, cardiomyocytes were absent due to plasma cells infiltration. Additionally, connective tissue proliferation can be admitted. Hemorrhagic zones are recognized around vessels, also in some cases neutrophils, eosinophils can be visualized (Fig. 4-8).

\section{Tentative Diagnoses were Leptospirosis with} Secondary Myocarditis

In $10 \mathrm{~h}$ after administration of amiodarone, stable sinus rhythm was obtained. Due to economic issues, three days after biopsy dog was sent home with the ambulatory treatment protocol, included: a combination of doxycycline $10 \mathrm{mg} / \mathrm{kg}$ BID and ampicillin $20 \mathrm{mg} / \mathrm{kg}$ BID, amiodarone $10 \mathrm{mg} / \mathrm{kg}$ BID, ramipril $0,125 \mathrm{mg} / \mathrm{kg}$ SID for next 4 weeks. After treatment, all medications were canceled. Five months after, the dog still stable, without any symptoms.

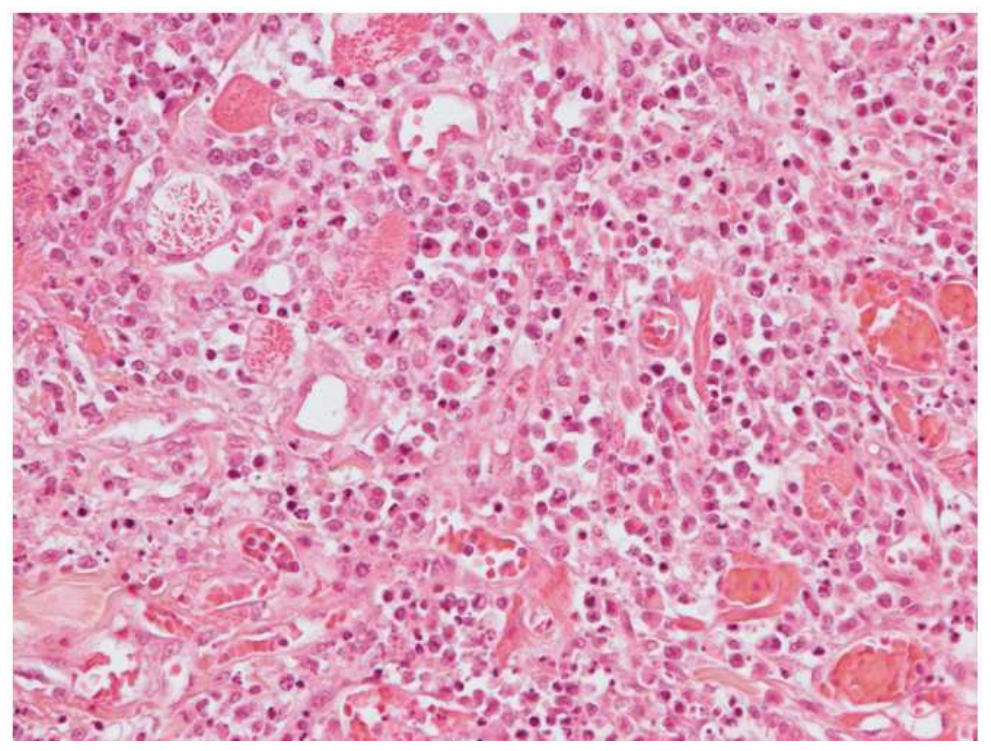

Fig. 4: Biopsy obtained myocardial tissue. Severe infiltration of myocardium by inflammatory cells, including lymphocytes, eosinophils, and neutrophils. Signs of periarteritis. Cardiomyocytes are almost eliminated. Several myocardial cells are present with different stages of degeneration (Hematoxiline\&Eosin x20)

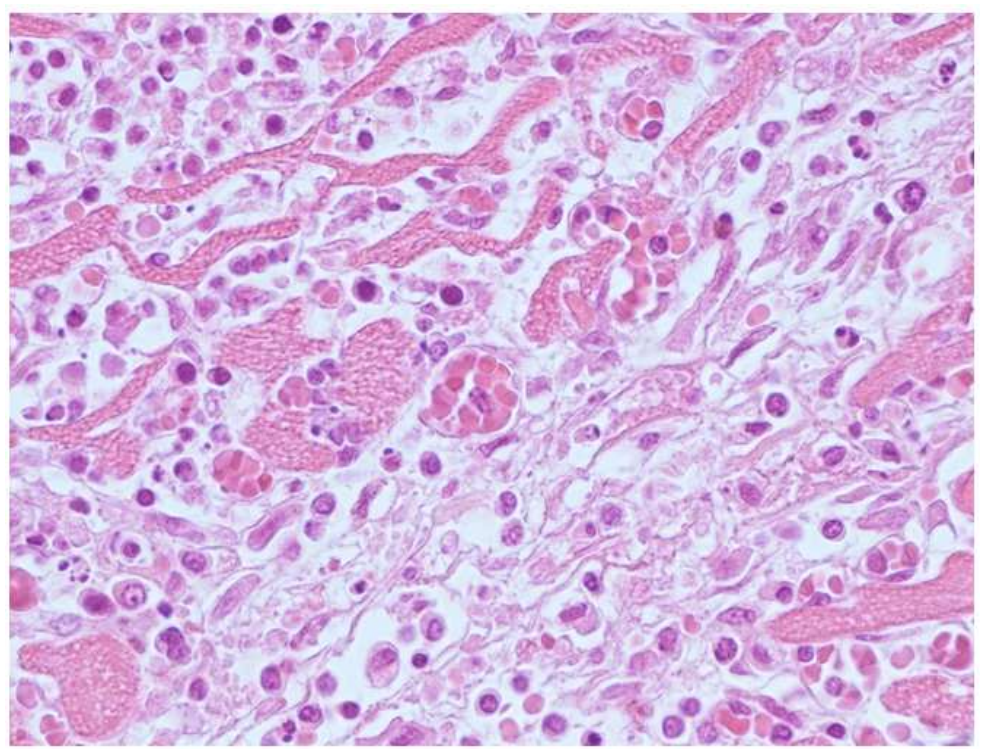

Fig. 5: Biopsy obtained myocardial tissue. Lymphocytic infiltration with degenerating cardiomyocytes (Hematoxiline\&Eosin $x 40$ ) 


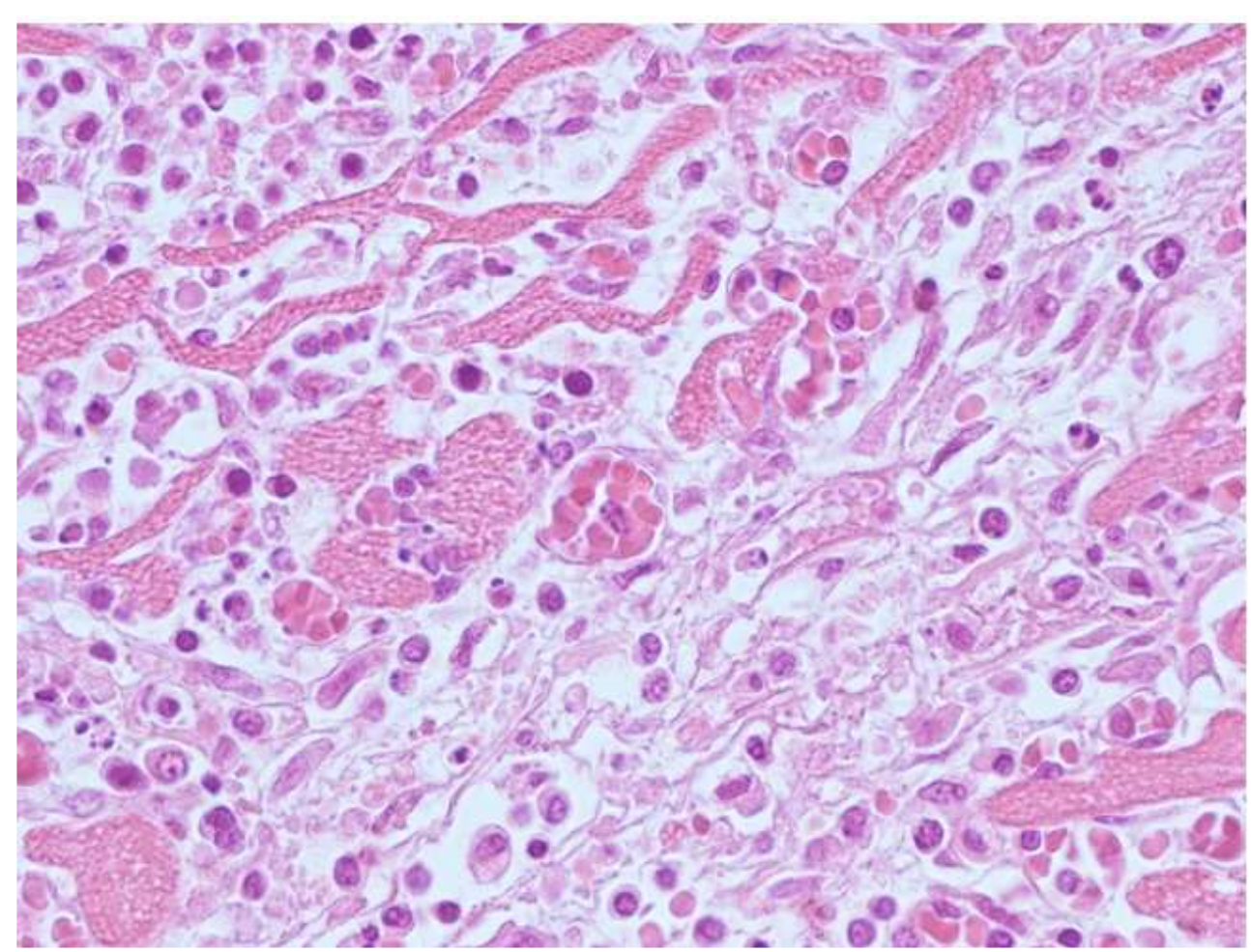

Fig. 6: Biopsy obtained myocardial tissue. Degenerated myocardial cells with mixed cell infiltration and signs of vasculitis. On microphotograph presented lymphocytes, neutrophils, some eosinophils, erythrocytes, several vacuolated endotheliocytes (Hematoxiline\&Eosin $\mathrm{x} 40$ )

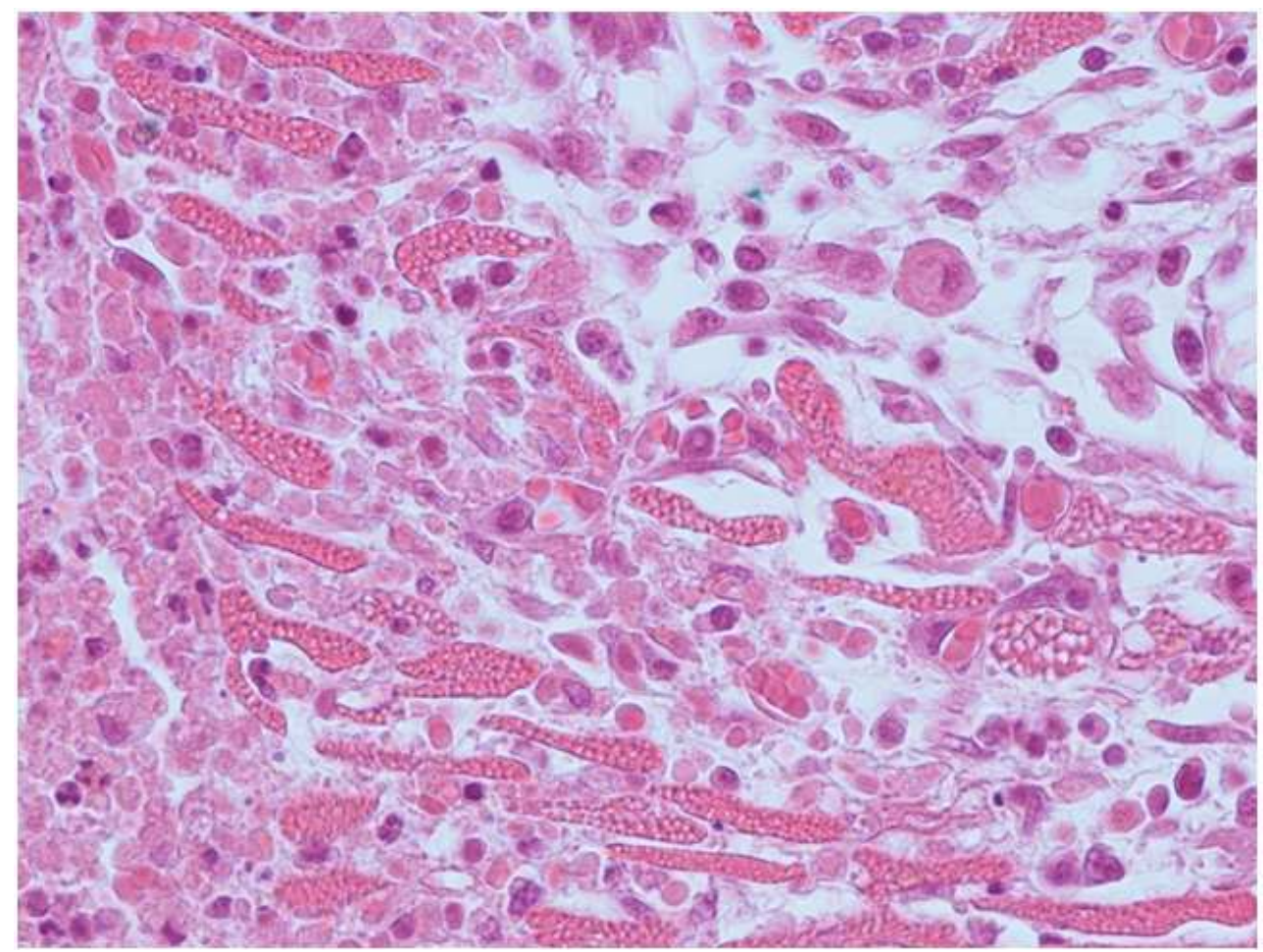

Fig. 7: Biopsy obtained myocardial tissue. Vacuolised, with signs of coagulative necrosis cardiomyocytes. Lymphocytic infiltration, fibroblast proliferation. In the right corner, one Anichkov cell can be visualized (Hematoxiline\&Eosin x40) 


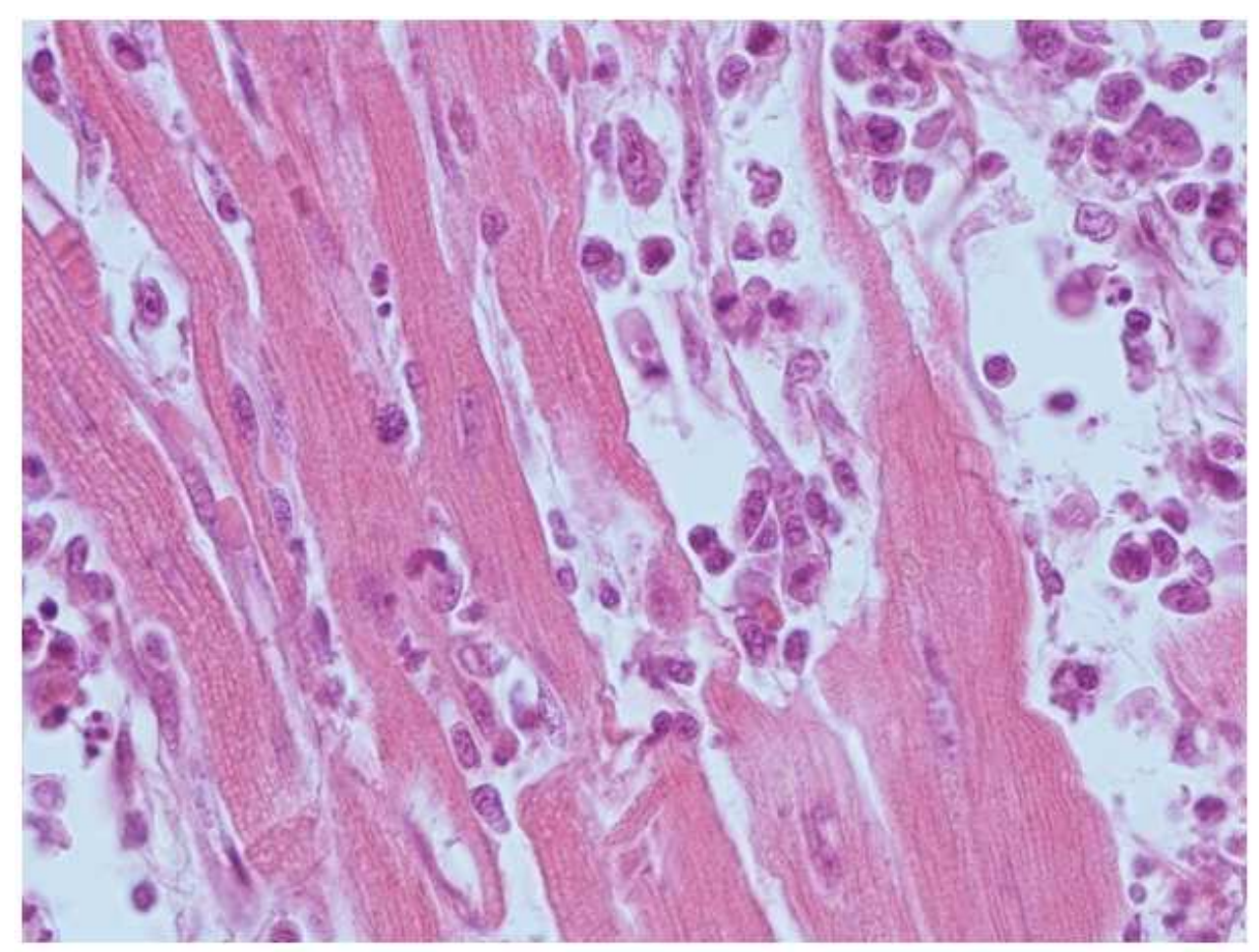

Fig. 8: Biopsy obtained myocardial tissue. Lymphocytic infiltration, some fibroblasts can be recognized. Cardiomyocytes of mild degeneration. (Hematoxiline\&Eosin $\mathrm{x} 40$ )

\section{Discussion and Conclusion}

Leptospirosis is a widespread zoonotic disease, occurring in humans (Levett, 2001), dogs (Alton et al., 2009), rarely cats (Agunloye and Nash, 1996; Mylonakis et al., 2005). In addition, it can infect more than 150 mammalian species (Kohn et al., 2009). In dogs, the disease usually caused by Leptospirainterrogans, the most common serovars are Icterohaemorrhagie, Canicola, Pomona, Autumnalis (Mylonakis et al., 2003; Kohn et al., 2010). The severity of infection in dogs mostly depended from infecting strain, endemic situation, host immune condition. In some cases dogs show mild or no signs of infection, sometimes it can lead to a severe form of illness and even death, due to polyorganic failure. A veterinarian should suspect Leptospira spp. infection in cases of renal, hepatic failure, febrile illness, pulmonary hemorrhage. Symptomatic phase usually associated with septicemia, presenting patients with acute renal failure, shivering, muscle tenderness, vomiting, diarrhea, dehydration and lethargy (Adin and Cowgill, 2000; Guedes et al., 2009). Dogs also could be presented with icterus, hepatic failure, dyspnea due to leptospiral pulmonary hemorrhage syndrome (Kohn et al., 2010; Goldstein et al., 2006). In some cases, hematuria can be identified (Birnbaum et al., 1998). Coagulation dysfunction can also occur with petechial hemorrhages. These signs are usually a combination of progressing hepatic failure and disseminated intravascular coagulation, associated with direct spirochetes vascular damage. Developing vasculitis can be the cause of mild ascites and hydrothorax, peripheral edema. Rarely ECG changes admitted in dogs (Mastrorilli et al., 2007), what can be explained by intracardial-vasculitis or inflammation.

The final diagnosis is based on PCR tests, microagglutination test, ELISA assays. However, sometimes even these tests with high specificity and sensitivity could be a false negative, especially if the test performed more than 10 days after active clinical manifestation and history of antibiotics (Gaschen, 2008). In this clinical case, we observed a negative blood PCR test, possibly, due to previous antibiotic therapy and immunosuppression by prednisone.

In Russian Federation leptospirosis is unequally presented due to different climatic zones, landscape and area. Recent data from Ministry of Agriculture RF shows several regions in central Russia with stable centers of leptospirosis, while several regions have rare or sporadic cases of Leptospira spp. infection. The most of data are collected from cattle husbandry and we have a lack of information for small domestic animals. In clinical practice of City veterinary oncology center "Pride" (Saint-Petersburg, Russia), canine leptospirosis is sporadic. This can be explained by the specific profile of the clinic and can't reflect the situation in general. 
In veterinary literature, there is a lack of data of myocardial involvement in the leptospirosis patients (Loftis et al., 2014). Myocardial failure of the inflammatory origins underdiagnosed due to the difficulties associated with methods of identification. The gold standard in myocarditis investigation is endomyocardial biopsy (Magnani et al., 2006). There are publications dedicated to myocarditis diagnostic (Agudelo et al., 2011; Guedes et al., 2009; NoszczykNowak et al., 2014; Santilli et al., 2017; Tyszko et al., 2007; Woolley et al., 2007) and much less about the endovascular biopsy. In human medicine, the most common causes of myocarditis are viral agents and more rarely non-virus genera (Borr. burgdoferi, T. cruzi, C. diphtheria), autoimmune diseases and intoxication (Kindermann et al., 2012). In veterinary medicine, inflammatory cardiomyopathies are only at the start of the investigation, but several agents are known for dogs 10 and they are mostly similar to humans.

Leptospirosis-mediated myocarditis is an uncommon disease even in human medicine, it is rarely defined and most data are known from endemic regions (Kularatne et al., 2011; Navinan and Rajapakse, 2012; Panagopoulos et al., 2014; Rajiv et al., 1996; Ranawaka et al., 2013; Shah et al., 2010; Turhan et al., 2008). In veterinary literature, there is a lack of data of myocardial involvement in leptospirosis patients (Loftis et al., 2014).

In this dog, we observed slowly progressing disease with the non-specific manifestation of myocardium inflammation. Clinical signs primarily admitted in this dog, including electrolyte disturbances and stable hypoglycemia, may be connected with the prolonged state of systemic inflammation, immunosuppression and endogenic glucocorticoid secretion decrease due to prednisone-mediated effects. This state is supported by performed ACHT-test for Addison's disease and subfebrile-febrile hyperthermia, what provided continuous muscle tremor and rapid glucose utilization. Troponin test showed a mild increase, which didn't reflect the severity of myocardial damage. This may be explained by the fact of previous immunosuppression with glucocorticoids Echocardiography findings are associated with disseminated inflammation zones and myocardial injury. These lesions provide changed geometry left ventricular cavity and impaired local contractility. ECG findings can be described by the formation of a functional re-entry circuit, which triggered by ectopic ventricular beats. Also, these zones could have own ectopic activity, due to inflammation barriers and isolation or configuration of isthmuses. The confirmation of isolated ventricular re-entry circle is associated with the independence of the ectopic rhythm from sinus depolarisation, but retrograde sinus activation could be suspected due to the presence of rare afterventricular premature complexes pause before sinus complex. A severe form of myocardium lymphocytic infiltration is supposed to be connected with developing vasculitis and perivascular tissues, characterized by hyperreactivity and, possibly, autosensibilisation (Kumar et al., 2014). Appeared cytotoxic effects associated with significant cardiomyocytes damage in variable forms and severity.

This clinical case to our mind is one of the rare manifestations of leptospirosis-mediated heart complications and first histologically proved in vivo leptospirosis associated myocarditis.

\section{Acknowledgment}

Special thanks to Koroleva M.A. for patient presentation.

\section{Author's Contributions}

Oleinikov Dmitrii: Collected data, provided diagnostics and treatment, coordinated the data-analysis and contributed to the writing of the manuscript.

Letunoskaja Anna: Contributed to the diagnostics and the writing of the manuscript.

\section{Ethics}

This article is original and contains unpublished material. The corresponding author confirms that all of the other authors have read and approved the manuscript and there are no ethical issues involved.

\section{References}

Adin, C.A. and L.D. Cowgill, 2000. Treatment and outcome of dogs with leptospirosis: 36 cases (19901998). J. Am. Vet. Med. Assoc., 216: 371-375.

DOI: $10.2460 /$ javma.2000.216.371

Agudelo, C.F., P. Schanilec, K. Kybicova and P. Kohout, 2011. Cardiac manifestations of borreliosis in a dog: A case report. Vet Med-Czech., 56: 85-92. DOI: $10.17221 / 1577-V E T M E D$

Agunloye, C.A. and A.S. Nash, 1996. Investigation of possible leptospiral infection in cats in Scotland. J. Small Anim. Pract., 37: 126-129. DOI: $10.1111 / \mathrm{j} .1748-5827.1996 . t b 02360 . \mathrm{x}$

Alton, G.D., O. Berke and R. Reid-Smith, 2009. Increase in seroprevalence of canine leptospirosis and its risk factors, Ontario 1998-2006. Can J. Vet. Res., 73: 167-175.

Andre-Fontaine, G., C. Branger and A.W. Gray, 2003. Comparison of the efficacy of three commercial bacterins in preventing canine leptospirosis. Vet. Rec., 153: 165-169. DOI: 10.1136/vr.153.6.165 
Birnbaum, N., S.C. Barr and S.A. Center, 1998. Naturally acquired leptospirosis in 36 dogs: Serological and clinicopathological features. J. Small Anim. Pract., 39: 231-236.

DOI: $10.1111 /$ j.1748-5827.1998.tb03640.x

Gaschen, F., 2008. Canine leptospirosis. Proceedings of the World Small Animal Veterinary Association World Congress, Aug. 20-24, Dublin, Ireland.

Goldstein, R.E., R.C. Lin and C.E. Langston, 2006. Influence of infecting serogroup on clinical features of leptospirosis in dogs. J. Vet. Intern. Med., 20: 489-494. DOI: 10.1111/j.1939-1676.2006.tb02886.x

Guedes, P.M.M., V.M. Veloso, L.C.C. Afonso, M.V. Caliari and C.M. Carneiro et al., 2009. Development of chronic cardiomyopathy in canine Chagas disease correlates with high IFN- $\gamma$, TNF- $\alpha$ and low IL-10 production during the acute infection phase. Vet. Immunol. Immunop.

Kindermann, I., C. Barth, F. Mahfoud, C. Ukena and M. Lenski et al., 2012. Update on myocarditis. J. Am. Coll. Cardiol., 59: 779-92. DOI: 10.1016/j.jacc.2011.09.074

Ko, A.I., C. Goarant and M. Picardeau, 2009. Leptospira: The dawn of the molecular genetics era for an emerging zoonotic pathogen. Nat. Rev. Microbiol., 7: 736-747. DOI: 10.1038/nrmicro2208

Kohn, B., K. Steinicke and G. Arndt, 2010. Pulmonary abnormalities in dogs with leptospirosis. J. Vet. Intern. Med., 24: 1277-1282. DOI: $10.1111 / \mathrm{j} .1939-1676.2010 .0585 . \mathrm{x}$

Kularatne, S.A., B.D. Budagoda, V.K. de Alwis, W.M. Wickramasinghe and J.M. Bandara et al., 2011. High efficacy of bolus methylprednisone in severe leptospirosis: a descriptive study in Sri Lanka. Postgrad. Med. J., 87: 13-7. DOI: $10.1136 /$ pgmj.2009.092734

Kumar, V., A.K. Abbas and J.C. Aster, 2014. Hypersensitivity: Immunologically mediated tissue injury. Robbins and Cotran Pathologic Basis of Disease, 9th Edn., Elsevier Health Sciences, pp: 200-11.

Levett, P.N., 2001. Leptospirosis. Clin. Microbiol Rev., 14: 296-326.

DOI: $10.1128 / C M R .14 .2 .296-326.2001$

Loftis, A., F. Castilllo-Alcala, L. Bogdanovich and A. Verma, 2014. Fatal canine leptospirosis on St. Kitts. Vet. Sci., 1: 150-158. DOI: 10.3390/vetsci1030150

Magnani, J.W., H.J. Danik, G.W. Dec Jr. and T.G. DiSalvo, 2006. Survival in biopsy-proven myocarditis: A long-term retrospective analysis of the histopathologic, clinical and hemodynamic predictors. Am. Heart J., 151: 463-70.

DOI: $10.1016 /$ j.ahj.2005.03.037
Mastrorilli, C., F. Dondi and C. Agnoli, 2007. Clinicopathologic features and outcome predictors of LeptospirainterrogansAustralisserogroup infection in dogs: A retrospective study of 20 cases (2001-2004). J. Vet. Intern. Med., 21: 3-10. DOI: 10.1111/j.1939-1676.2007.tb02921.x

Mylonakis, M.E., E. Bourtzi-Hatzopoulou and A.F. Koutinas, 2005. Leptospiralseroepidemiology in a feline hospital population in Greece. Vet. Rec., 156: 615-616. DOI: 10.1136/vr.156.19.615

Navinan, M.R. and S. Rajapakse, 2012. Cardiac involvement in Leptospirosis. Trans. R Soc. Trop. Med. Hyg., 106: 515-20.

DOI: $10.1016 /$ j.trstmh.2012.06.007

Noszczyk-Nowak, A., M. Nowak, A. Cepiel, R. Ciaputa and U. Pasławska et al., 2014. Myocarditis in dogs: etiology, clinical and histopathological features (11 cases: 2007-2013). Ir. Vet. J. 67: 28. DOI: $10.1186 / \mathrm{s} 13620-014-0028-8$

Panagopoulos, P., I. Terzi, M. Karanikas, N. Galanopoulos and E. Maltezos, 2014. Myocarditis, pancreatitis, polyarthritis, mononeuritis multiplex and vasculitis with symmetrical peripheral gangrene of the lower extremities as a rare presentation of leptospirosis: A case report and review of the literature. J. Med. Case Reports, 8: 150. DOI: $10.1186 / 1752-1947-8-150$

Rajiv, C., R.J. Manjuran, N. Sudhayakumar and M. Haneef, 1996. Cardiovascular involvement in Leptospirosis. Indian Heart J., 48: 691-4.

Ranawaka, N., V. Jeevagan, P. Karunanayake and S. Jayasinghe, 2013. Pancreatitis and myocarditis followed by pulmonary hemorrhage, a rare presentation of leptospirosis- A case report and literature survey. BMC Infect. Dis., 13: 38.

DOI: $10.1186 / 1471-2334-13-38$

Santilli, R.A., S. Battaia, M. Perego, M. Tursi and E. Grego et al., 2017. Bartonella-associated inflammatory cardiomyopathy in a dog. J. Vet. Cardiol., 19: 74-81. DOI: 10.1016/j.jvc.2016.07.005

Shah, K., G.P. Amonkar, R.N. Kamat and J.R. Deshpande, 2010. Cardiac findings in leptospirosis. J. Clin. Pathol., 63; 119-23. DOI: $10.1136 /$ jcp.2009.069575

Turhan, V., N. Ozmen, E. Ulusoy, M. Aparcl and M. Gur, 2008. Cardiac Leptospirosis, a case report and review. Anatol. J. Clin. Investig., 3: 54-6.

Tyszko, C., J.M. Bright and S.L. Swist, 2007. Recurrent supraventricular arrhythmias in a dog with atrial myocarditis and gastritis. J. Small Anim. Pract., 48: 335-338. DOI: 10.1111/j.1748-5827.2007.00337.x

Woolley, R., R. Blundell, R. Else, B. Corcoran and C. Devine et al., 2007. Atrial myocarditis as a cause of sinus arrest in a dog. J. Small AnimPract., 48: 455-457. DOI: $10.1111 / \mathrm{j} .1748-5827.2006 .00256 . \mathrm{x}$ 